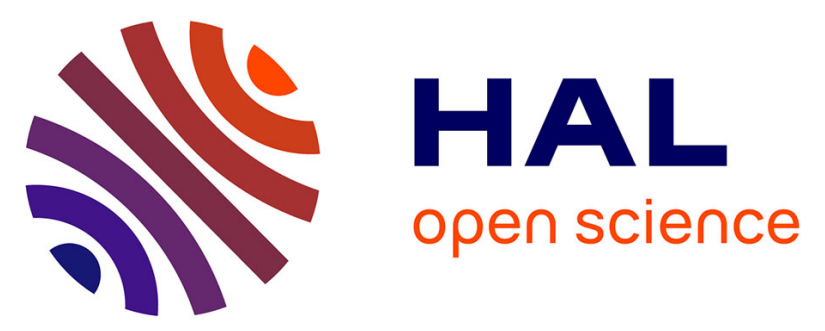

\title{
Impact of the statistical method, training dataset, and spatial scale of post-processing to adjust ensemble forecasts of the height of new snow
}

Jari-Pekka Nousu, Matthieu Lafaysse, Guillaume Evin, Matthieu Vernay, Joseph Bellier, Bruno Joly, Maxime Taillardat, Mickaël Zamo

\section{To cite this version:}

Jari-Pekka Nousu, Matthieu Lafaysse, Guillaume Evin, Matthieu Vernay, Joseph Bellier, et al.. Impact of the statistical method, training dataset, and spatial scale of post-processing to adjust ensemble forecasts of the height of new snow. EGU General Assembly Conference, EGU, May 2020, Virtual, France. hal-02912563

\section{HAL Id: hal-02912563 \\ https://hal.inrae.fr/hal-02912563}

Submitted on 6 Aug 2020

HAL is a multi-disciplinary open access archive for the deposit and dissemination of scientific research documents, whether they are published or not. The documents may come from teaching and research institutions in France or abroad, or from public or private research centers.
L'archive ouverte pluridisciplinaire HAL, est destinée au dépôt et à la diffusion de documents scientifiques de niveau recherche, publiés ou non, émanant des établissements d'enseignement et de recherche français ou étrangers, des laboratoires publics ou privés. 


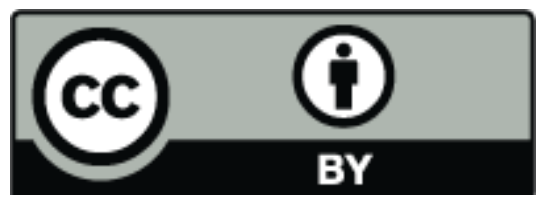

\section{Impact of the statistical method, training} dataset, and spatial scale of post-processing to adjust ensemble forecasts of the height of new snow

Jari-Pekka Nousu ${ }^{1,2}$, Matthieu Lafaysse ${ }^{1}$, Guillaume Evin ${ }^{3}$ Matthieu Vernay ${ }^{1}$, Joseph Bellier ${ }^{4,5}$, Bruno Joly ${ }^{6}$, Maxime Taillardat ${ }^{6,7}$, Mickaël Zamo ${ }^{6,7}$ 
- Forecasting the height of new snow: - Safety and economic concerns

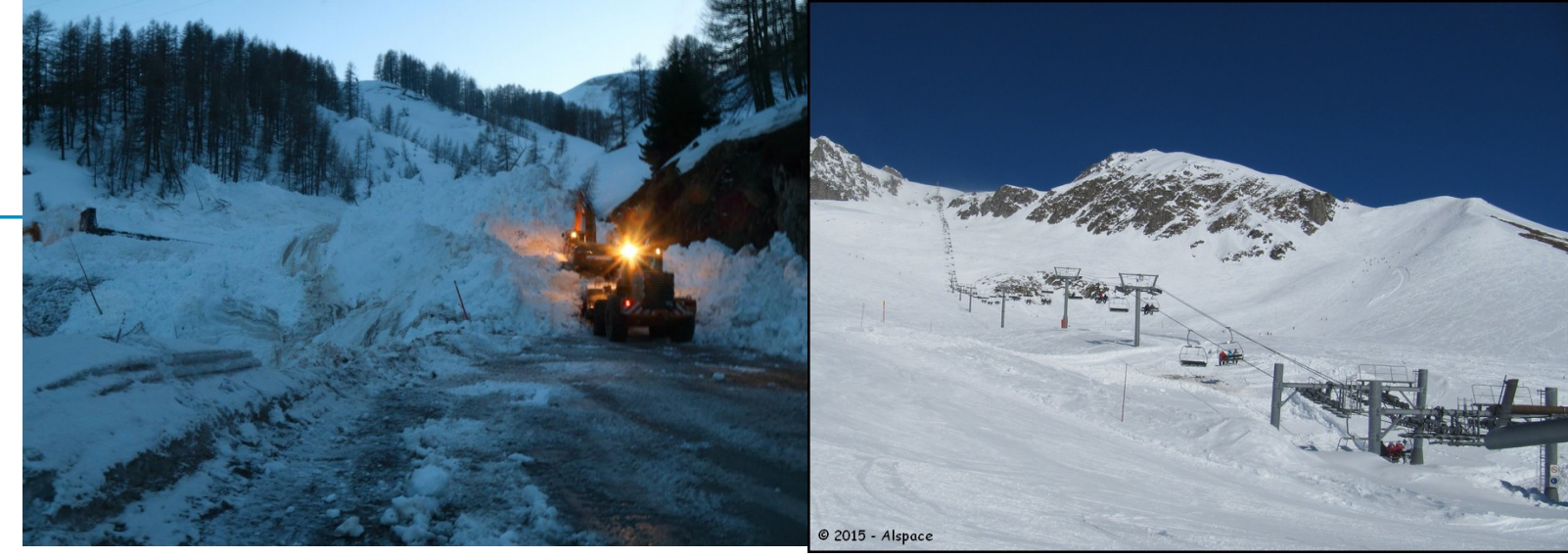

- Meteo-France automatic forecasts currently available (website and smartphone apps) : 24h height of new snow $=$

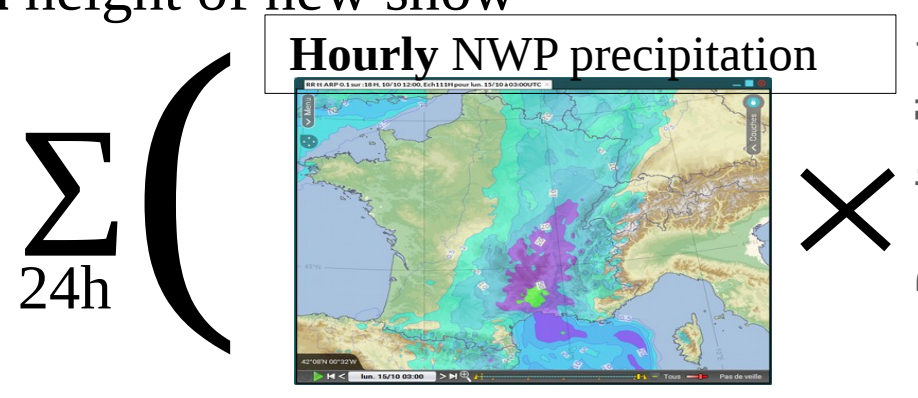

Compaction during snowfall
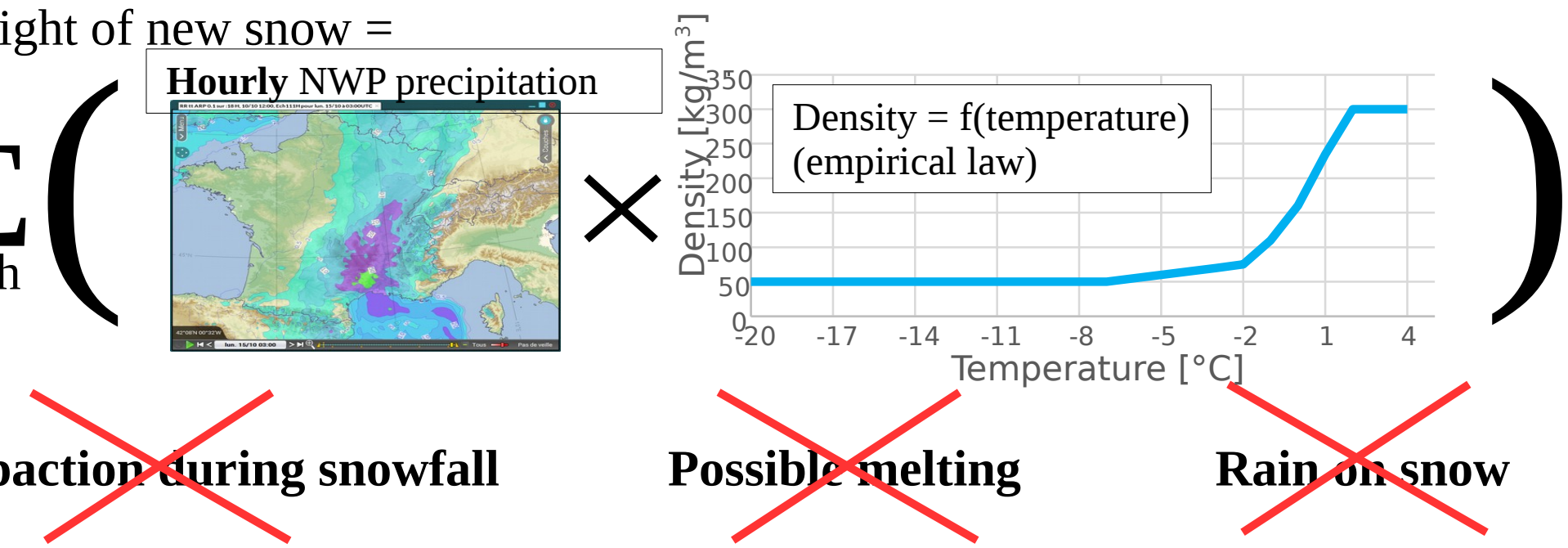


\section{Alternative: Physical modelling SAFRAN-Crocus}

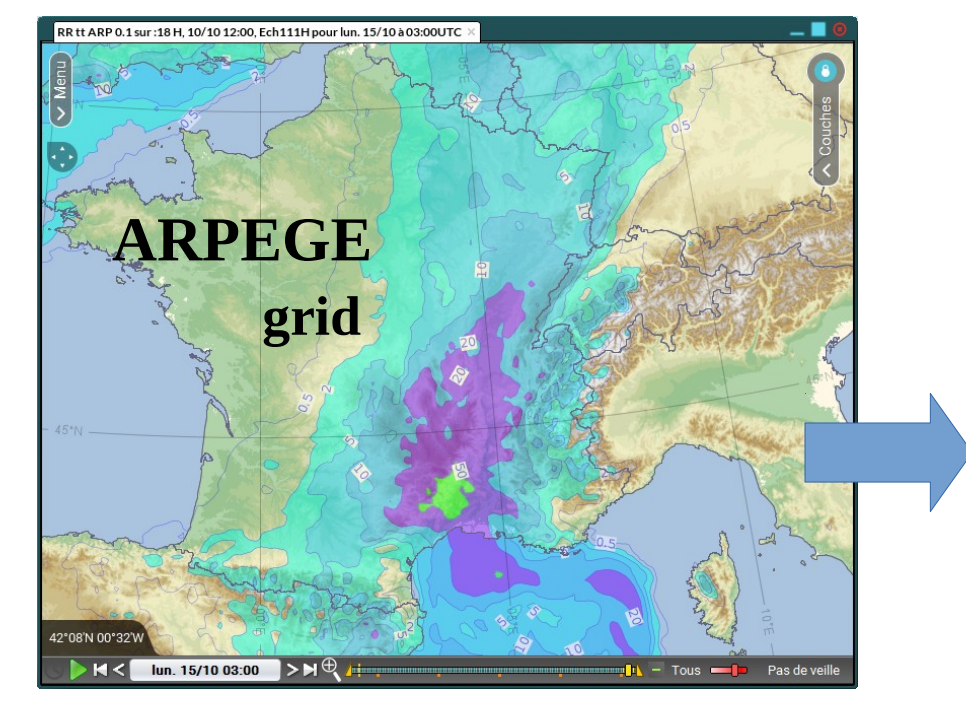

Durand et al., 1998

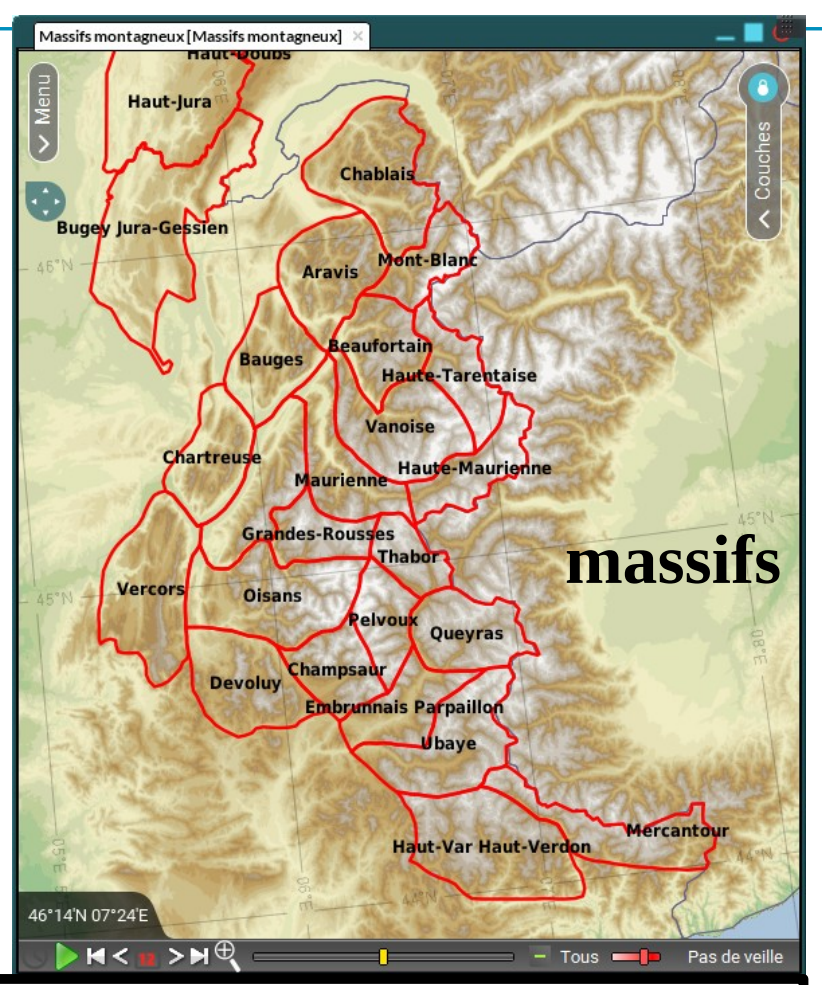

SAFRAN :

- Spatial aggregation of ARPEGE on massifs ( 1000 km²)

- Adjust meteorological variables at various elevations

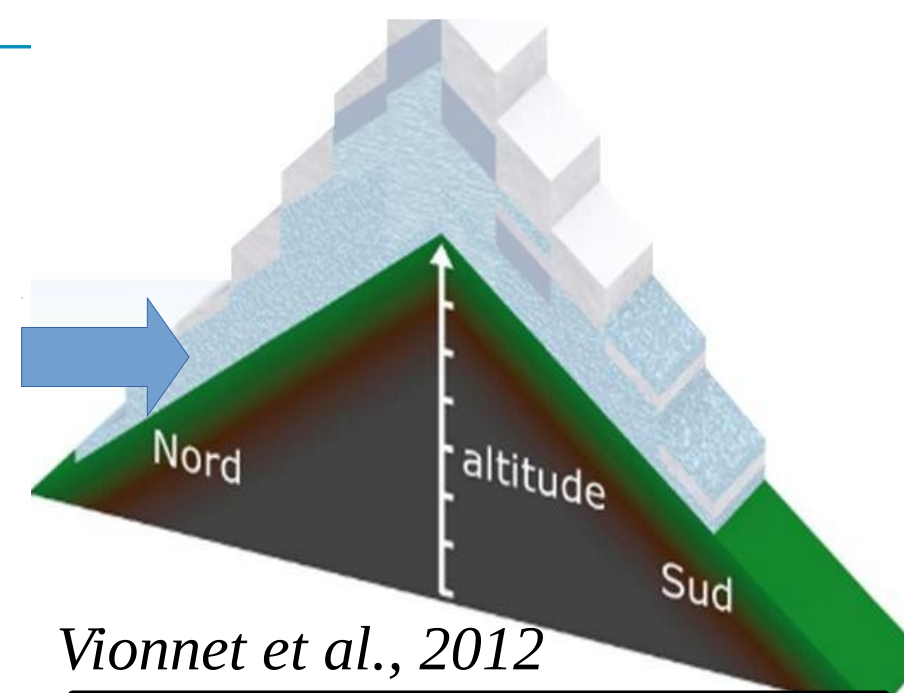

Crocus :

- Falling snow density = f(temperature, wind speed)

- Explicit mechanical compaction

- Melting (energy balance)

- Compaction due to liquid water (rain on snow) 


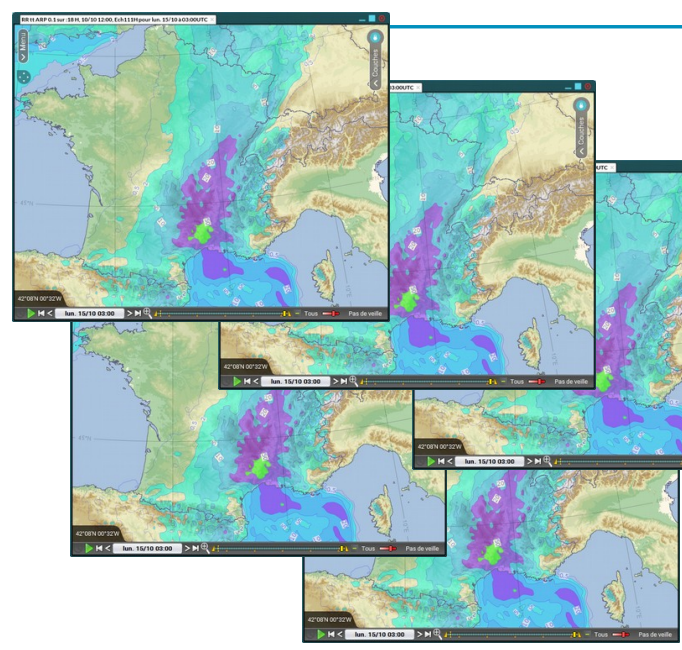

PEARP

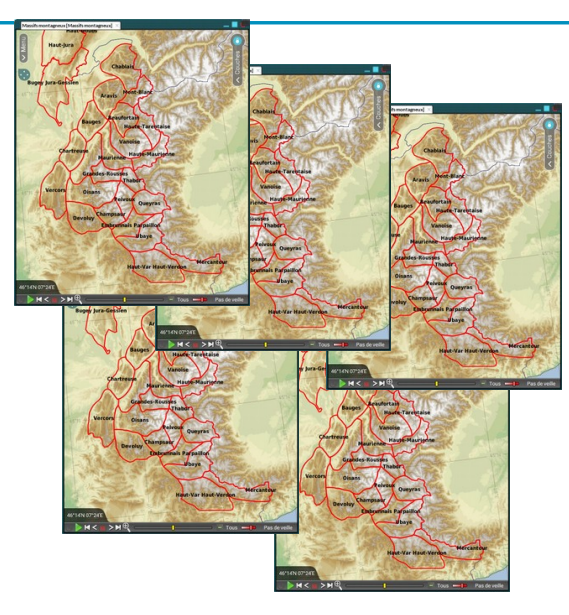

SAFRAN

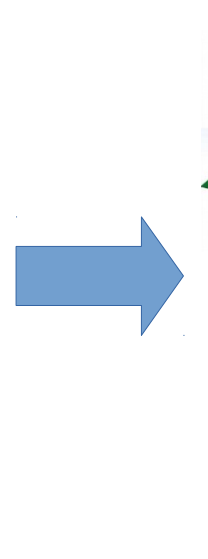

35 members

4-day forecast, Mercantour region, 2100 m elevation

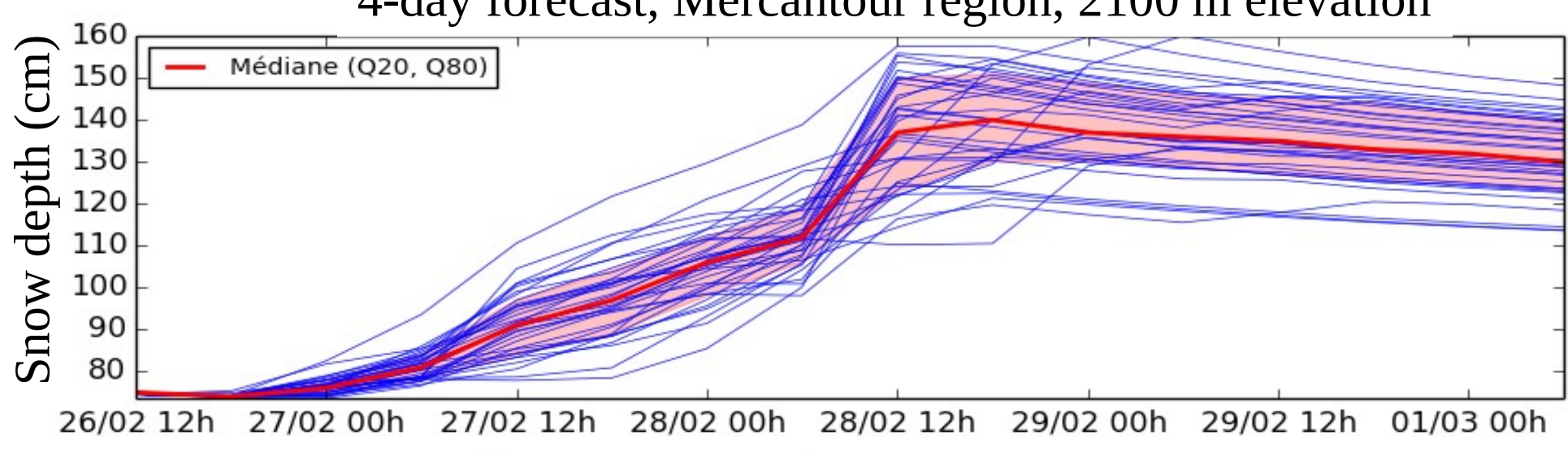

$C$ METEO FRANCE
Vernay et al. 2015

\section{Crocus}




\section{Rank diagram}
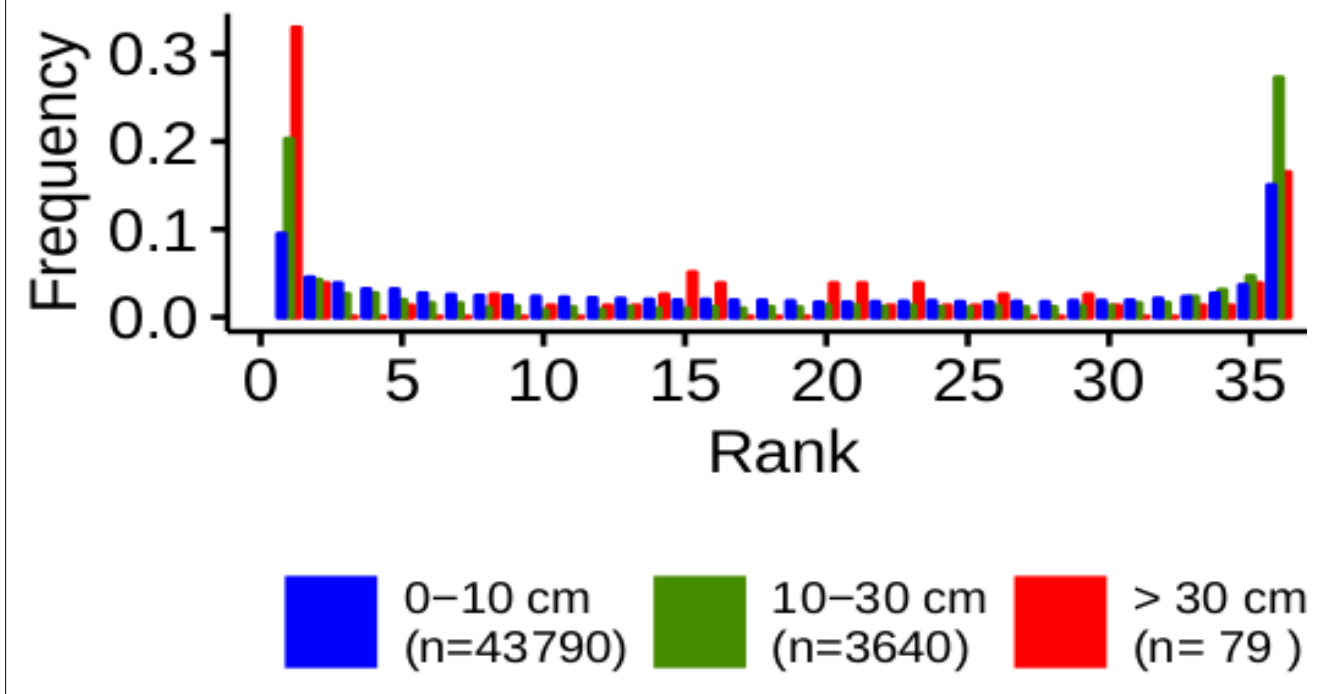

Underdispersion !

\section{Quantile-Quantile plot}

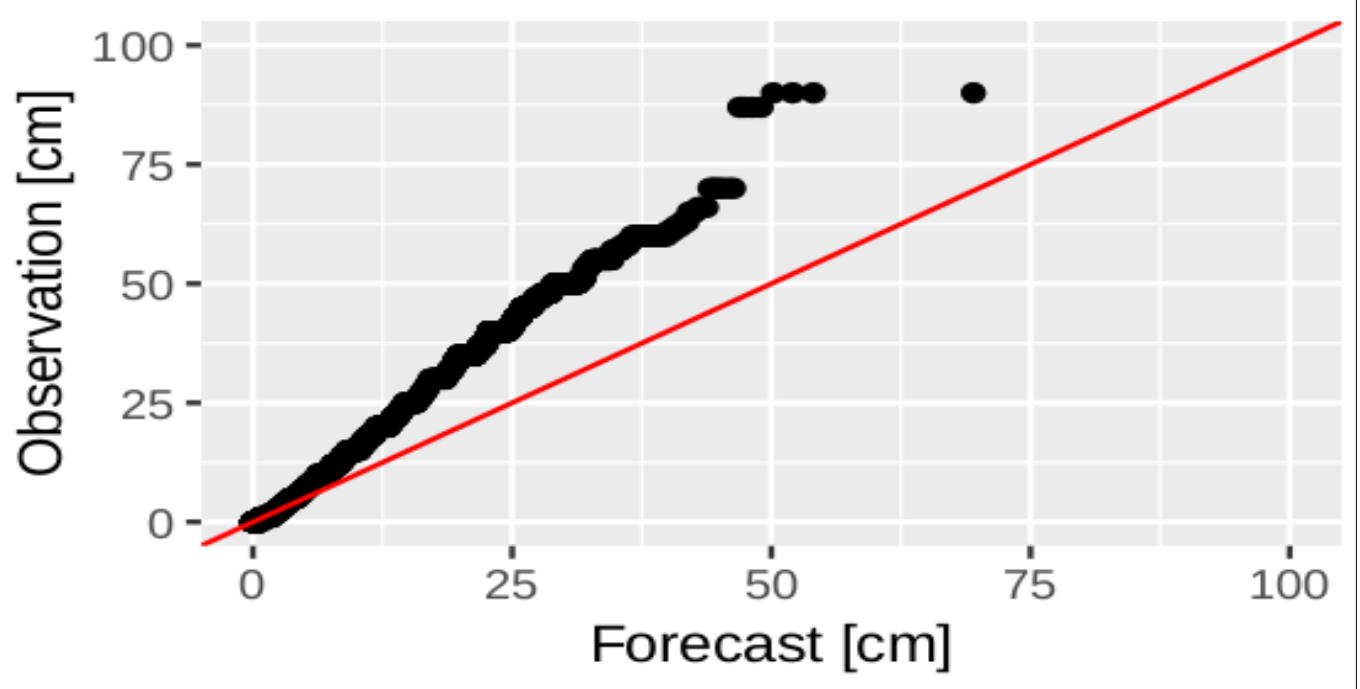

Bias ! 
- Physical ensemble modelling of the snowpack improves the forecast of the height of new snow compared to:

- Direct NWP outputs (Champavier et al., 2018)

- Deterministic systems (Vernay et al., 2015)

- Ensemble Model Output Statistics (EMOS) are useful to forecast the height of new snow from direct ensemble NWP outputs (precipitation and temperature)

(Stauffer et al., 2018 ; Scheuerer and Hamill, 2019)

- Quantile Regression Forests (QRF) can incorporate more predictors and have added value for precipitation forecasts (Taillardat et al., 2019)

\section{Questions}

- Can Ensemble Model Output Statistics (EMOS) improve the forecasts from physical modelling ?

- What is the best training dataset ?

- What is the spatial validity of the post-processing ?

- Can Quantile Regression Forests (QRF) improve the skill compared to EMOS ? 
- In Nousu et al., NPG, 2019, we apply the EMOS method used by Scheuerer and Hamill $(2015$; 2018) for precipitation forecasts:

- We assume that the conditional distribution of the forecast HN to the raw ensemble forecasts follow a Censored Shifted Gamma (CSG) defined by 3 parameters :

Mean $\mu$; Variance $\sigma^{2}$; Shift $\delta$.

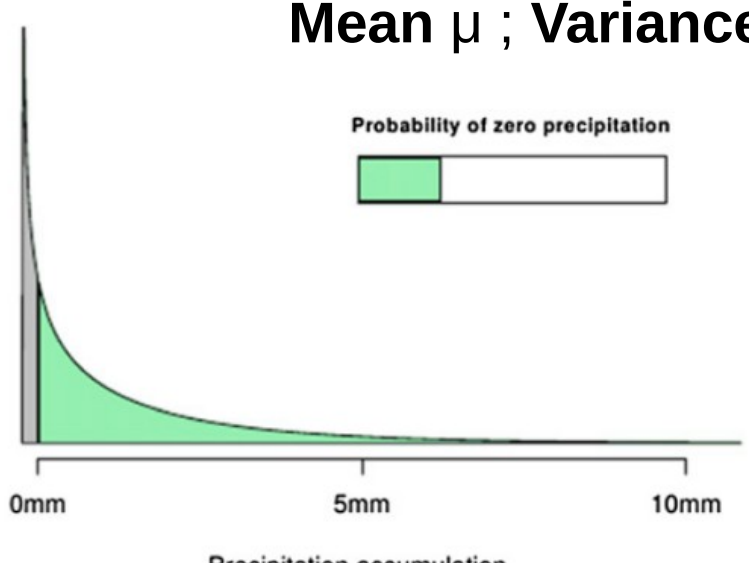

Precipitation accumulation

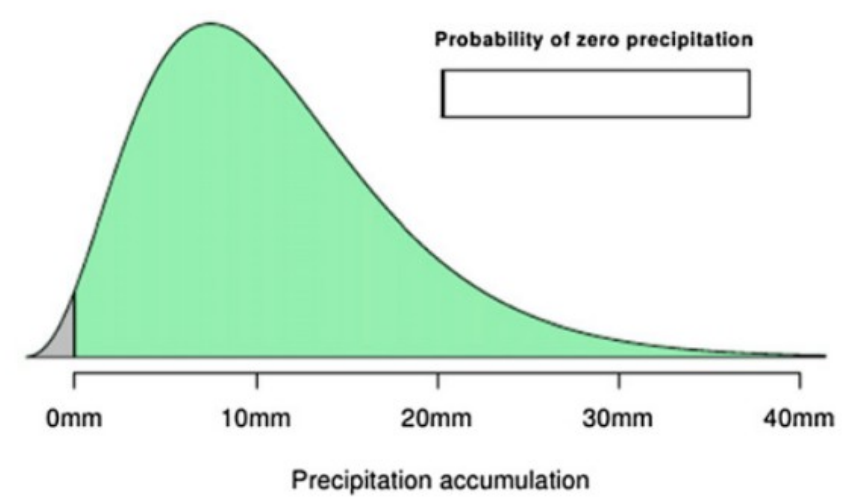

Density Histogram with PDFs

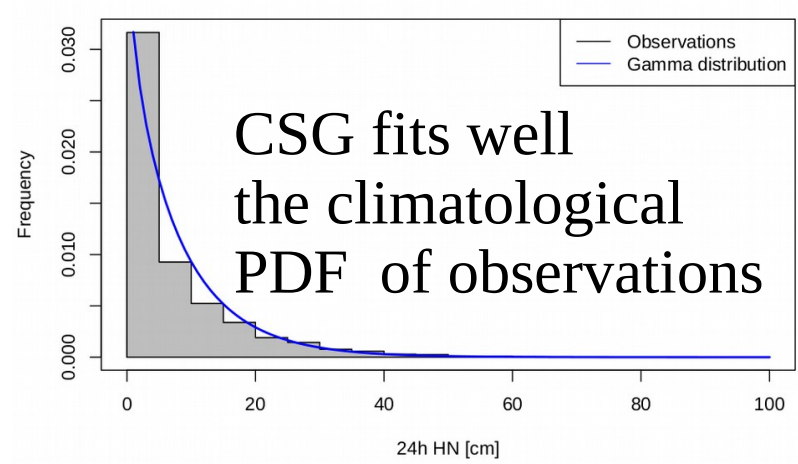

- $\quad$ Regression model between CSG parameters and synthetic properties of the raw ensemble (mean, dispersion, probability of $0 \mathrm{~cm}$ ) 


\section{Statistical post-processing: calibration}

Predictand :

Network of local observations of the 24h height of new snow

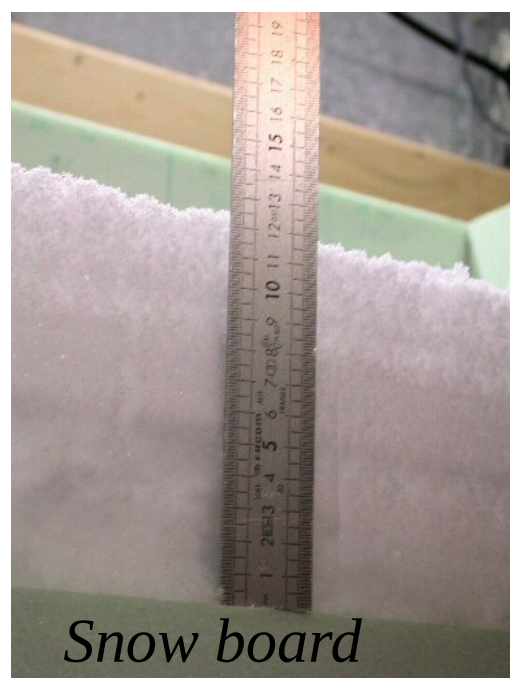

French Pyrenees

64

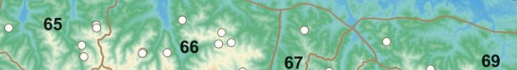
(x)
2 Predictor datasets: Ensemble forecasts PEARP-S2M

\begin{tabular}{ll|l|l|l|} 
& Period & Members & $\begin{array}{l}\text { Initial } \\
\text { conditions }\end{array}$ & $\begin{array}{l}\text { Resolution and } \\
\text { physics }\end{array}$ \\
\hline $\begin{array}{l}\text { Reforecast } \\
\begin{array}{l}\text { Real-time } \\
\text { forecasts }\end{array}\end{array}$ & $2014-2017$ & 35 & Perturbed & Heterogeneous \\
\hline
\end{tabular}

French

Alps

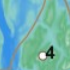

Spatial scale of the calibration:

- Massif scale

- Station scale
- From real-time forecasts, winter 2017-2018 


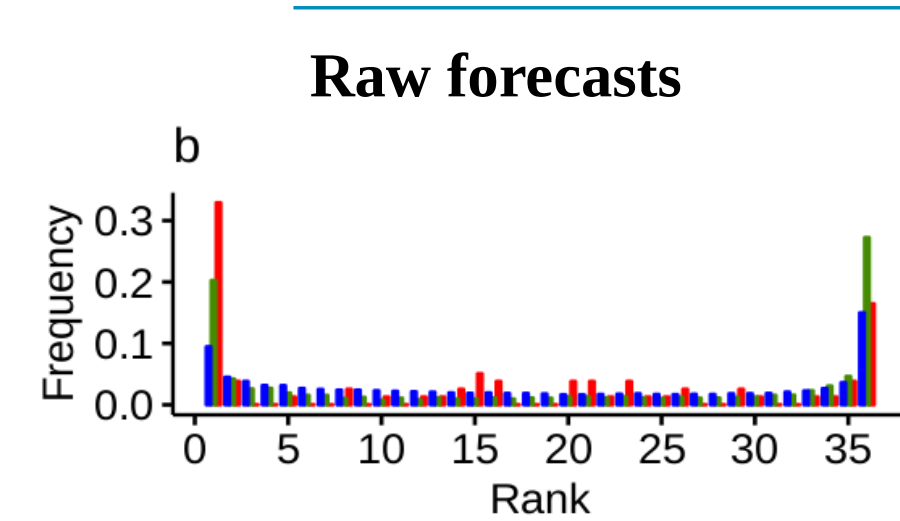

0-10 cm $(n=43790)$

10-30 cm $(n=3640)$

$>30 \mathrm{~cm}$ $(n=79)$

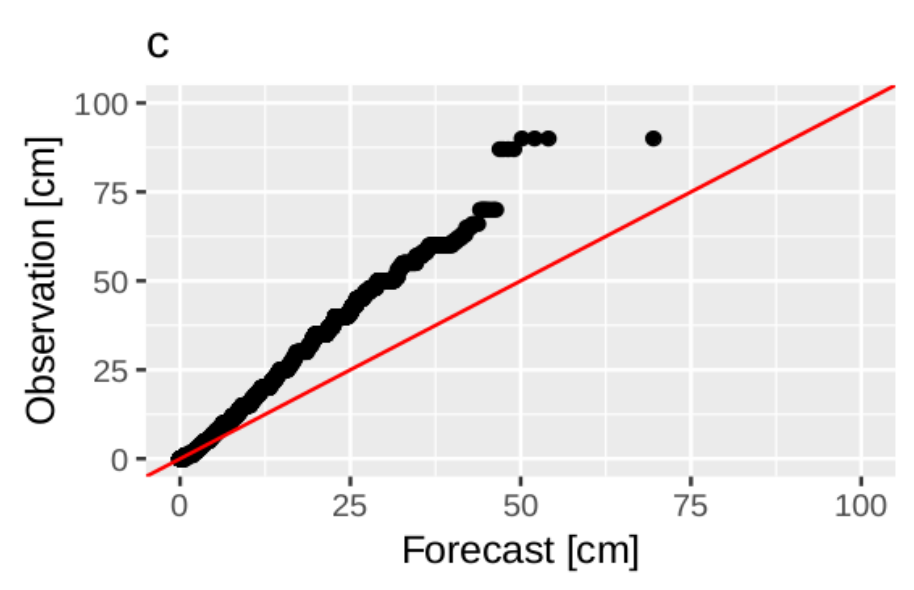

Corrected forecasts

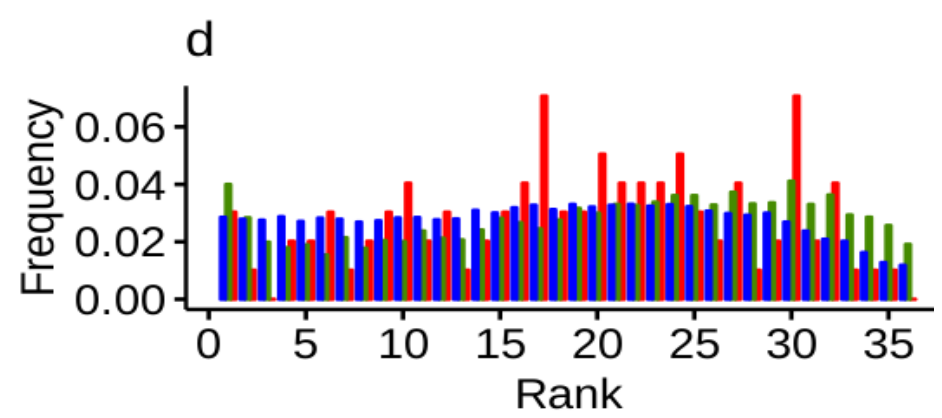

0-10 cm $(n=42229)$

$10-30 \mathrm{~cm}$ $(n=5181)$

$>30 \mathrm{~cm}$ $(n=99)$

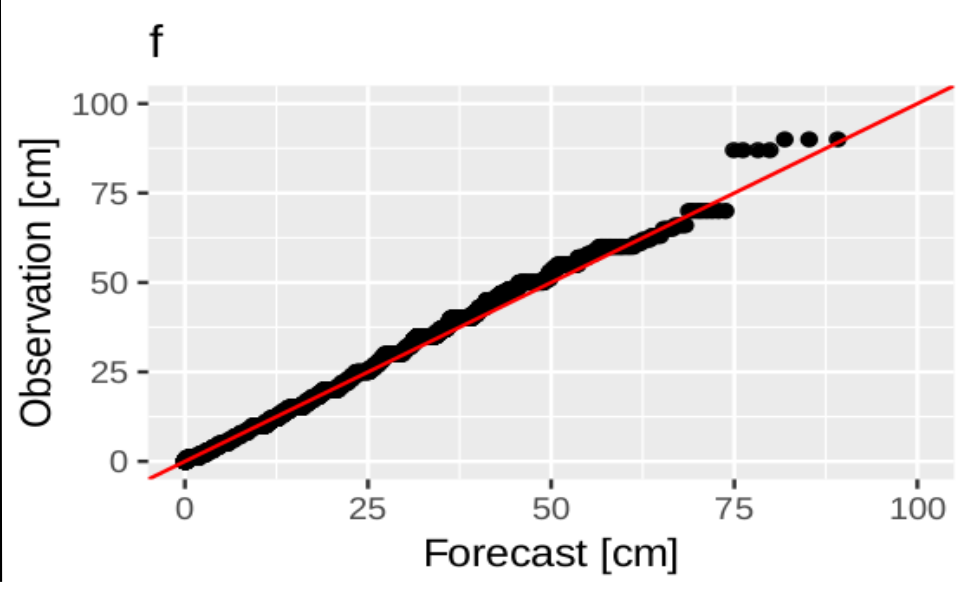

CRPSS (Reference : raw forecasts)

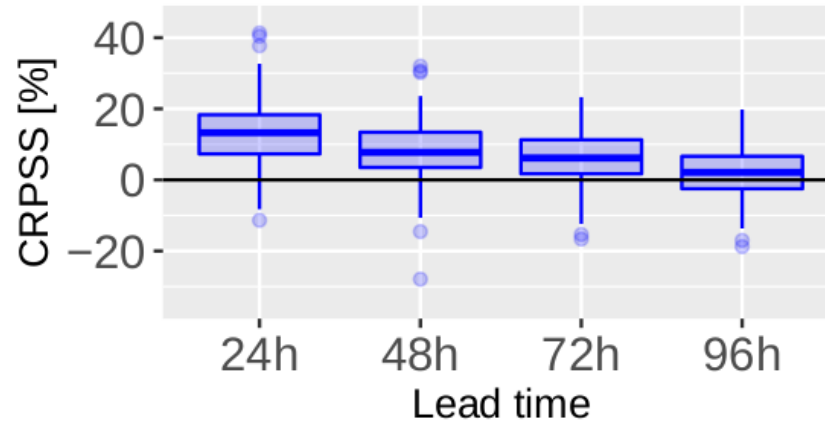

- Remove bias and underdispersion

- Improvement of CRPS on most stations.

- Larger improvement at short lead times 
Training:

reforecasts 1994-2016

Evaluation: real-time forecasts 2017-2018

ปे
$\frac{C}{0}$
$\frac{\partial}{0}$
$\frac{1}{1}$

0.15
0.10
0.05
0.00

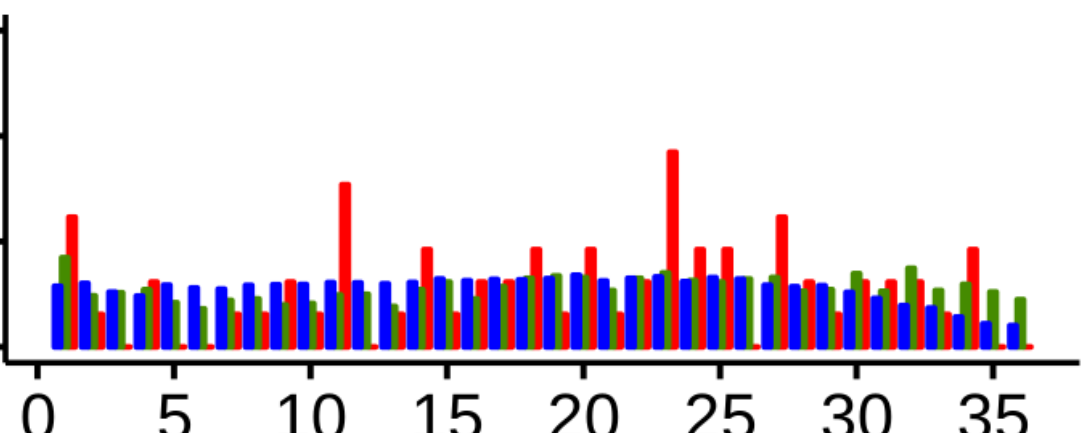

Training: real-time forecasts 2014-2017

Evaluation: real-time forecasts 2017-2018

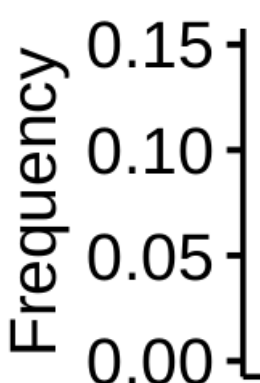

$\begin{array}{llllllll}0 & 5 & 10 & 15 & 20 & 25 & 30 & 35\end{array}$ Rank Rank

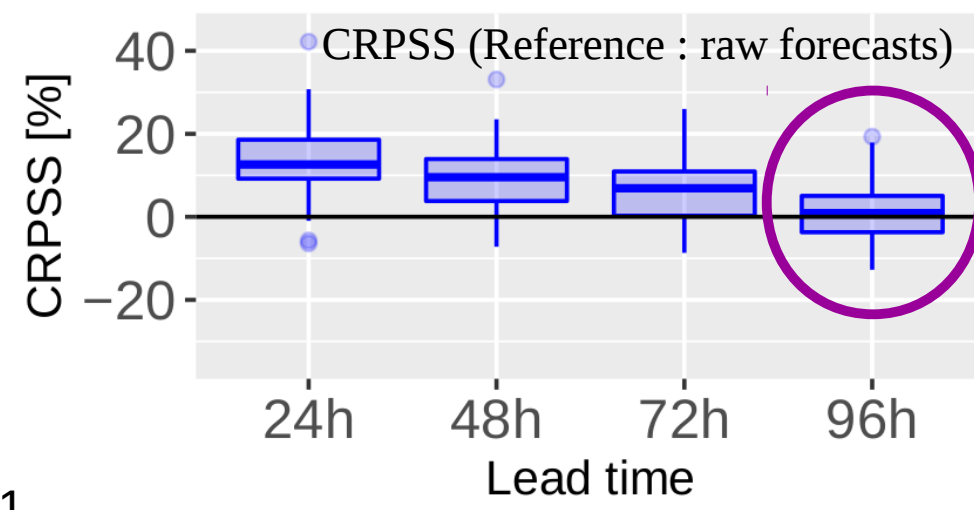

Page 1.
Pros and cons on both sides
Severe events less reliable Low events more reliable

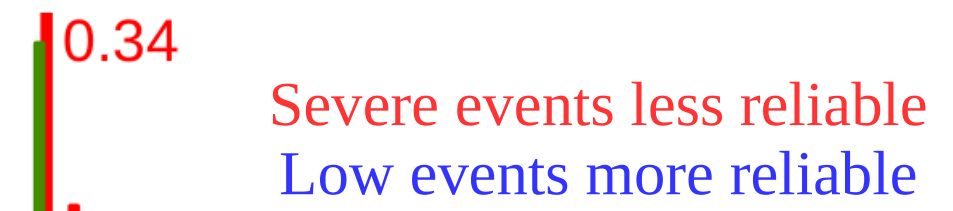

1.

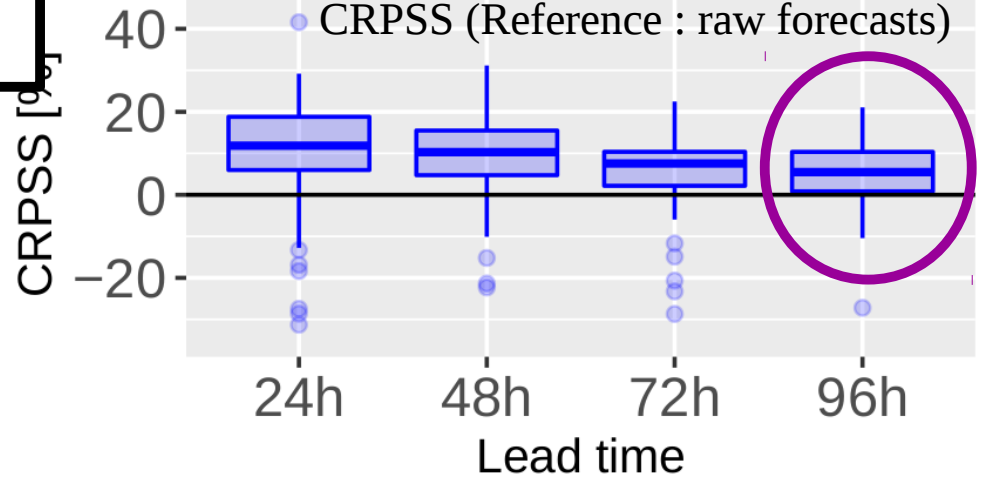

Better skill at the longest lead time 


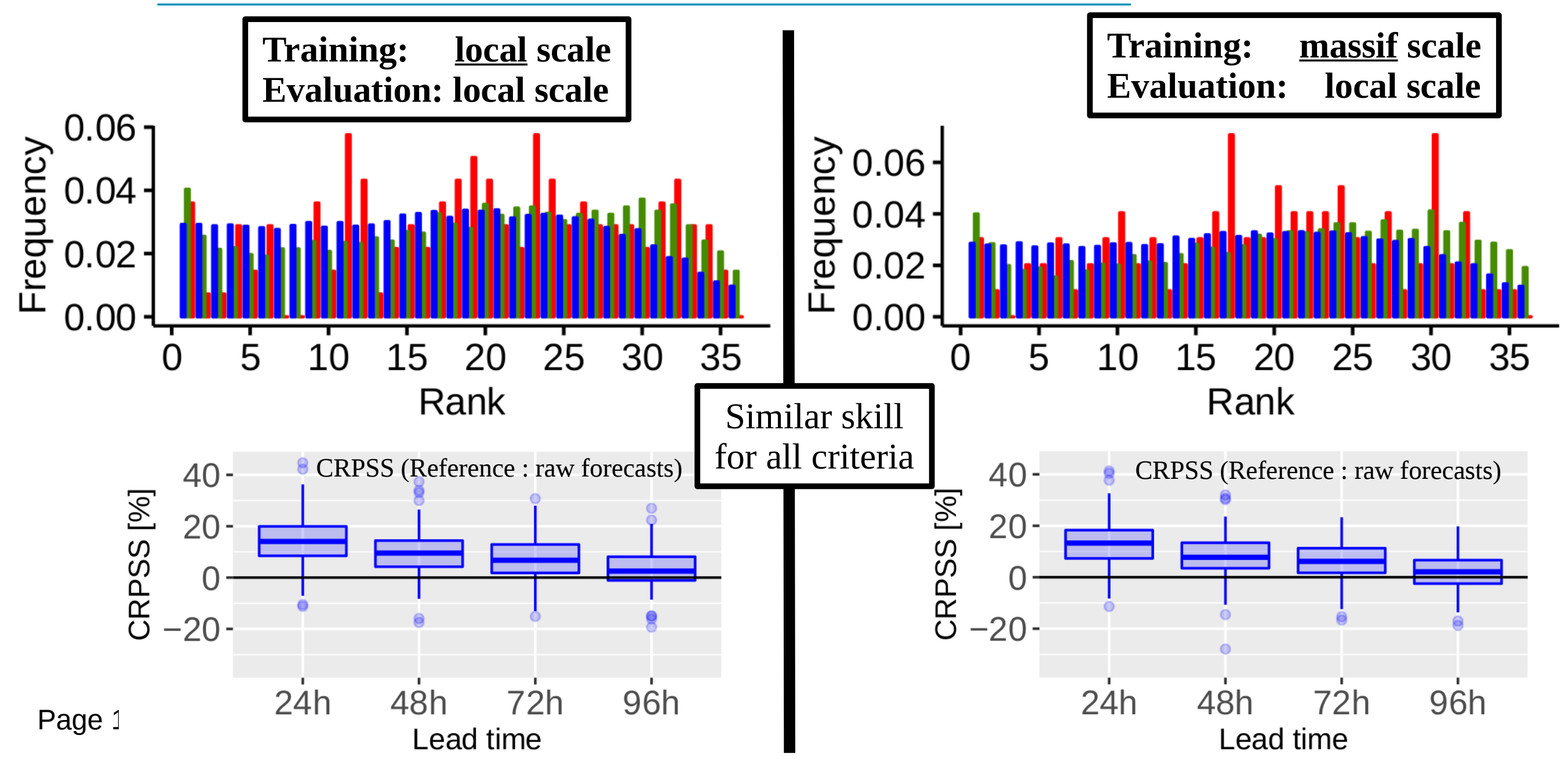


- The statistical properties of the post-processed are satisfactory in both cases (flat rank histograms for both EMOS and QRF)
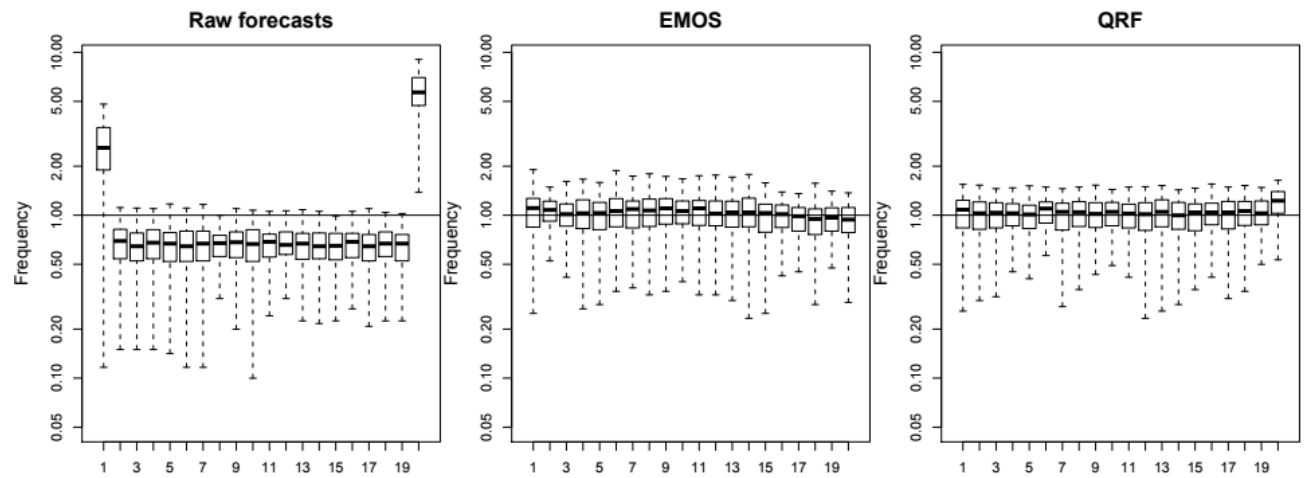

- A significant improvement of CRPS is obtained with QRF in theoretical experiments based on the 22-year reforecast dataset (22* [21-year training, 1-year validation] )

$\rightarrow$ Better predictive power

CRPS

Lead time: $24 \mathrm{~h}$

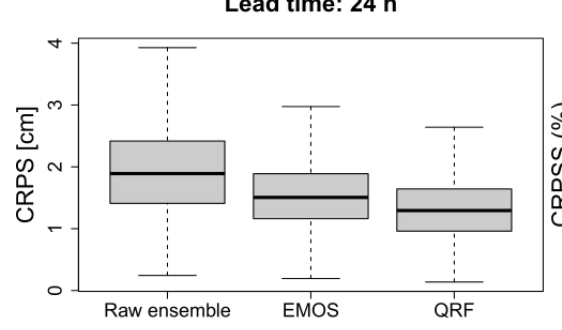

CRPSS vS QRF

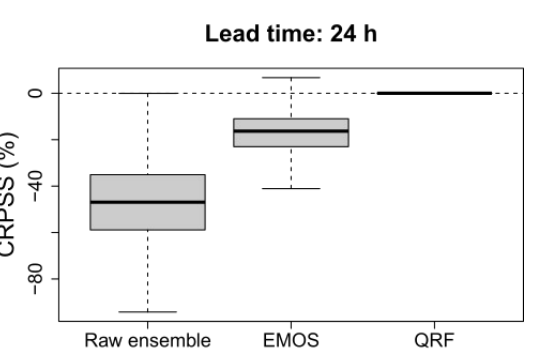

CRPS

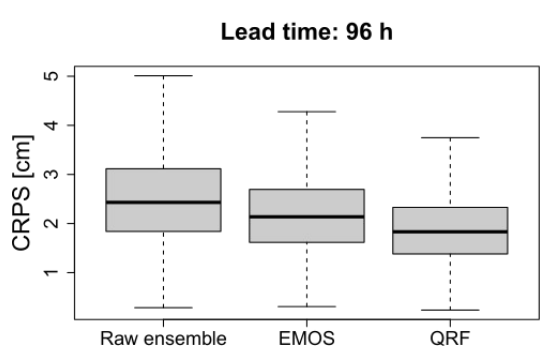

CRPSS vs QRF

Lead time: $96 \mathrm{~h}$

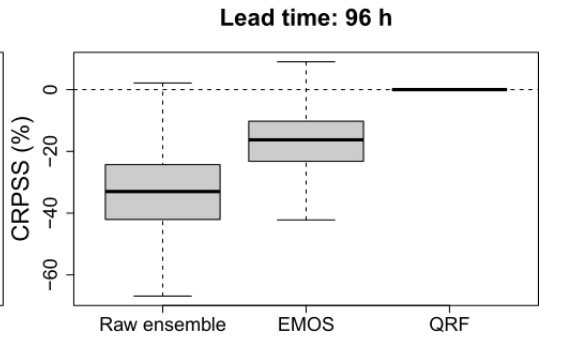


- $\quad$ Illustrations on specific cases (24h lead time forecasts):

Station $74134400-2000-01-15-2000-02-04$

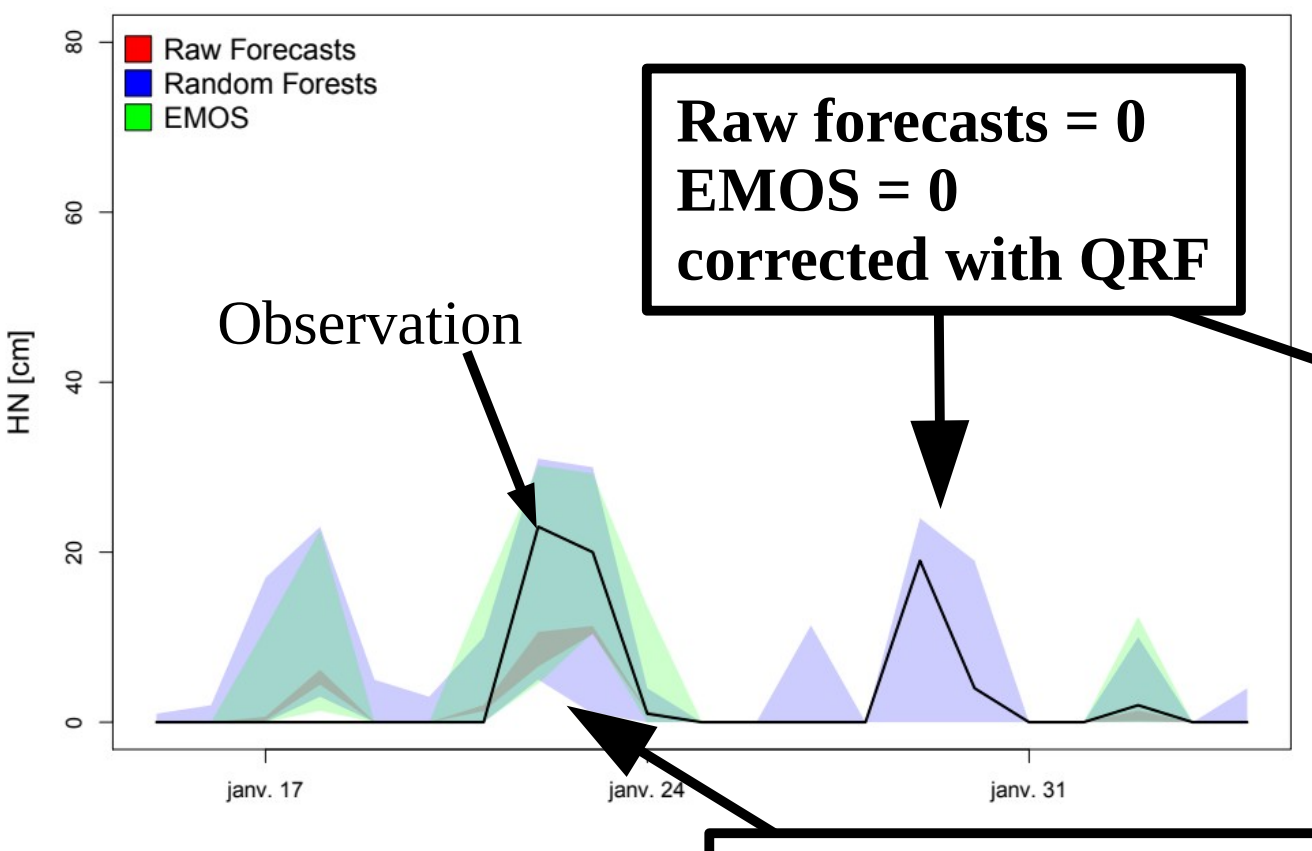

EMOS and QRF both correct the underdispersion and bias

of raw forecasts
Raw forecasts $=0$

EMOS $=0$
Station $73034400-2015-12-26-2016-01-15$

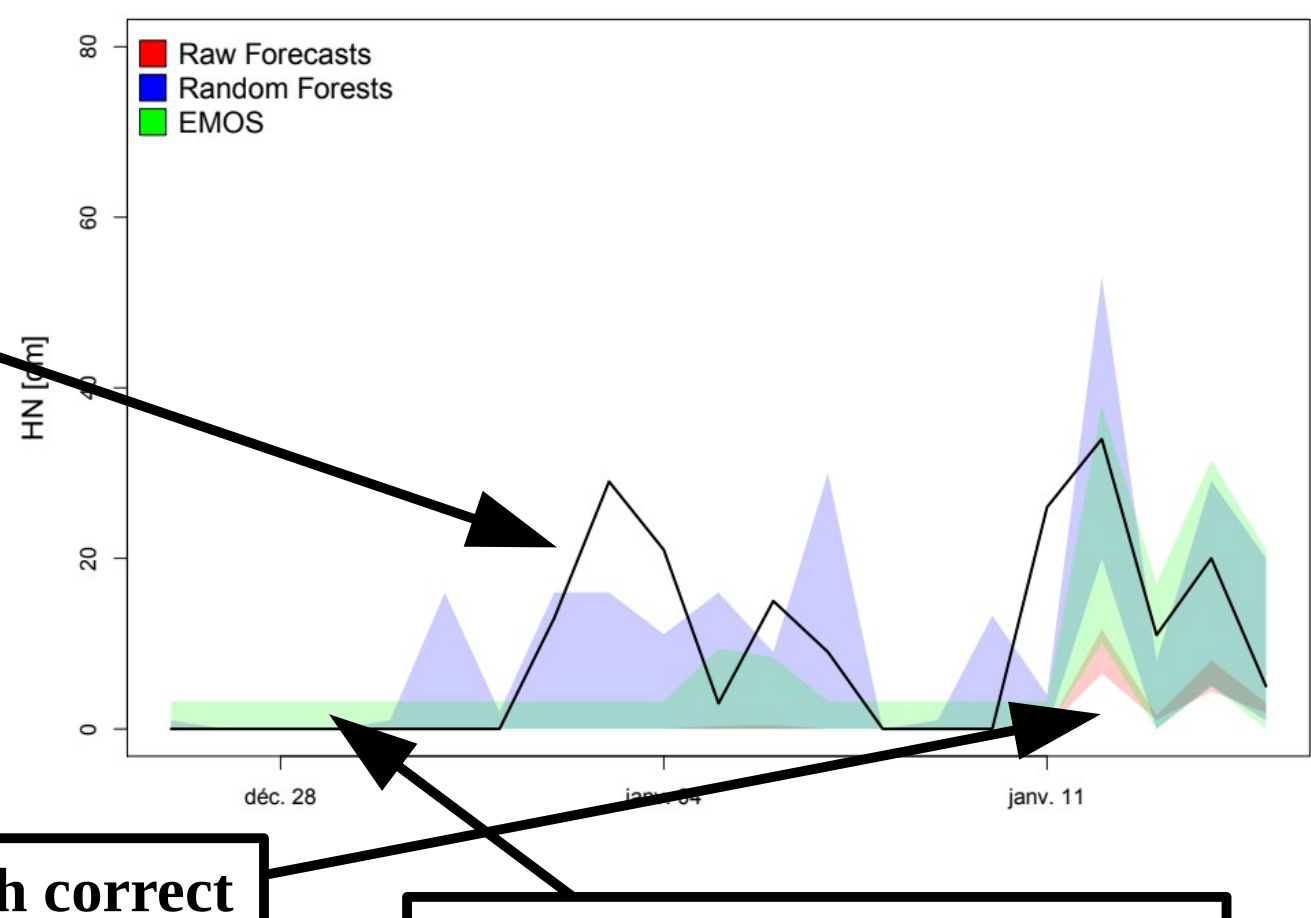

On dry days, QRF provides a lower spread than EMOS 
- Raw ensemble forecasts + snowpack modelling provide predictive but biased and underdispersive forecasts not well suited for automated products.

- Ensemble Model Output Statistics (EMOS) improve the forecasts from physical modelling.

- What is the best training dataset ?

$\rightarrow$ Long reforecasts improve the reliability of the post-processed forecasts for the severe and unusual events

$\rightarrow$ But they should me more homogeneous with the operational system (initial perturbations)

- What is the spatial validity of the post-processing ?

$\rightarrow$ Spatial consistence of biases allows to apply corrections at the massif scale $\left(1000 \mathrm{~km}^{2}\right)$

- Quantile Regression Forecasts (QRF)

- Better predictive skill in theoretical experiments thanks to other predictors

- $\quad$ Further work required to test the robustness when transfered to real time forecasts 


\section{More details for the EMOS results in our main reference:}

Nousu, J.-P., Lafaysse, M., Vernay, M., Bellier, J., Evin, G., and Joly, B.: Statistical post-processing of ensemble forecasts of the height of new snow, Nonlin. Processes Geophys., 26, 339-357, https://doi.org/10.5194/npg-26-339-2019, 2019.

\section{Other references}

Champavier, R., Lafaysse, M., Vernay, M., and Coléou, C.: Comparison of various forecast products of height of new snow in 24 hours on French ski resorts at different lead times, in: Proceedings of the International Snow Science Workshop - Innsbruck, Austria, pp. 1150-1155, http://arc.lib.montana.edu/snow-science/objects/ISSW2018_012.11.pdf, 2018.

Scheuerer, M. and Hamill, T. M.: Statistical Postprocessing of Ensemble Precipitation Forecasts by Fitting Censored, Shifted Gamma Distributions, Mon. Weather Rev., 143, 4578-4596, https://doi.org/10.1175/MWR-D-15-0061.1, 2015.

Scheuerer, M. and Hamill, T. M.: Generating Calibrated Ensembles of Physically Realistic, High-Resolution Precipitation Forecast Fields Based on GEFS Model Output, J. Hydrometeorol., 19, 1651-1670, https://doi.org/10.1175/JHM-D-18-0067.1, 2018.

Scheuerer, M. and Hamill, T. M.: Probabilistic Forecasting of Snowfall Amounts Using a Hybrid between a Parametric and an Analog Approach, Mon. Weather Rev., 147, 1047-1064, https://doi.org/10.1175/MWR-D-18-0273.1, 2019.

Stauffer, R., Mayr, G. J., Messner, J. W., and Zeileis, A.: Hourly probabilistic snow forecasts over complex terrain: a hybrid ensemble postprocessing approach, Adv. Stat. Climatol. Meteorol. Oceanogr., 4, 65-86, https://doi.org/10.5194/ascmo-4-65-2018, https://www.adv-statclim-meteorol-oceanogr.net/4/65/2018/, 2018.

Taillardat, M., Fougères, A., Naveau, P., and Mestre, O.: Forest-based and semi-parametric methods for the postprocessing of rainfall ensemble forecasting, Weather Forecast., in press, https://doi.org/10.1175/WAF-D-18-0149.1, 2019.

Vernay, M., Lafaysse, M., Merindol, L., Giraud, G., and Morin, S.: Ensemble Forecasting of snowpack conditions and avalanche hazard, Cold. Reg. Sci. Technol., 120, 251-262, https://doi.org/10.1016/j.coldregions.2015.04.010, 2015. 